\title{
A VULNERABILIDADE SOCIAL DAS CULTURAS MINORITÁRIAS NO BRASILCONTEMPORÂNEO: O CASO DOS ÍNDIOS TUXÁS
}

\author{
Alfredo Costa* \\ Brenner H. Maia-Rodrigues \\ Renato Martins Ferreira"
}

\section{Resumo}

Os processos referentes a inserção do indígena na cultura do consumo já foramlargamente discutidos por diversos autores oriundos de várias áreas do conhecimento. Pensaras relações entre povos de culturas diferentes, no que tange ao uso e ocupação de um espaço em comum, nos remete aos conceitos de exercício de poder e soberania. Em um mundo em que grande parte dos espaços está inserida na lógica da produção social do capitalismo global, no que diz respeito a sua constante revaloração, a vulnerabilidade das culturas minoritárias aflora como uma questão frágil, principalmente no que diz respeito ao reconhecimento formal e manutenção de seus territórios históricos, de seus hábitos, línguas e culturas. O povo Tuxá, original da região norte da Bahia, que foi deslocado de seu território tradicional em função da construção da represa de Luiz Gonzaga, na década de 80, nos fornece substratos para a discussão sobre a falta de interesse público em relação aos povos indígenas no Brasil. A análise das informações proveniente dos dados dos Censos Demográficos de 1991 e 2000 demonstra, juntamente a depoimentos obtidos em campo, que são nítidos os impactos decorrentes da inserção desses povos na lógica do capital. É esse embate que pretende-se evidenciar no presente texto.

Palavras-chave: Vulnerabilidade, Território, Cultura Indígena.

\footnotetext{
*LESTE/IGC/UFMG.

'LESTE/IGC/UFMG.

'LESTE/IGC/UFMG.

Cadernos do Leste

Artigos Cientificos
}

Belo Horizonte, Jan.-Dez. Vol.9, n9, 2009 
O Rio São Francisco, desde as nascentes em territórios mineiros até a foz entre Sergipe e Alagoas, tem sido alvo de projetos de modificação arquitetados por homens sonhadores de processos produtivos grandes e organizados e de energia farta. Esses projetos sempre esbarram no sonho de outros homens, de uma vida digna para si mesmos e para suas famílias no trabalho diário na terra. (Scott, 2006, p. 80)

\section{1- INTRODUÇÃO}

Tratar do processo de reconhecimento dos territórios indígenas na atual perspectiva brasileira é tarefa espinhosa. As contradições existentes entre os interesses políticos, industriais, indígenas e a própria opinião pública configuram-se tanto como um entrave à justa aplicação dos direitos históricos e culturais dos habitantes pré-coloniais quanto aos seus territórios.

Conhecimentos a respeito das “(...) sociedades ditas 'primitivas' são importantes não,como se crê às vezes, enquanto testemunho de nosso passado, mas como testemunho de umpresente que poderia ser outro: ela mostra, antes de tudo, que o modelo em que estamosimersos, de 'desenvolvimento' a qualquer custo, é apenas um entre os possíveis.'(Da Cunha,1989, apud De Paula, 2005, p. 09).

De modo geral, é possível conceber que em uma sociedade moderna o ser humanonão vive num meio natural, mas em meio tecnicamente construído, que interpõe uma rede demáquinas e técnicas apuradas entre o homem e a natureza. Em decorrência da expansão dosrecursos técnicos, a estrutura social torna-se mais complexa do que a da sociedadetradicional. (Garcia, 2000)

Mais, a ocidentalização, processo civilizatório associado à idéia de modernização(Latouche, 1996 apud Garnelo \& Sampaio, 2006), torna-se o padrão de referência oferecidopela sociedade dominante aos grupos subordinados, e pressupõe a mudança decomportamentos e valores, dentro da ótica européia e estadunidense atual (Ianni, 1995 apudGarnelo\& Sampaio, 2006).

Por outro lado, a ressignificação das etnicidades e regionalismos aparece como um desdobramento da modernidade. As relações indígenas, outrora restritas ao binômio extinção/assimilação, podem ser repensadas no âmbito da globalização (Garnelo\& Sampaio, 2006).

Deste modo, pensar nas relações entre povos de culturas diferentes, no que tange ao uso e ocupação de um espaço em comum, nos remete aos conceitos de exercício de poder esoberania. Em um mundo em que grande parte dos espaços estão inseridos na lógica do capitalismo global, no que diz respeito a sua constante revaloração, a vulnerabilidade das culturas ditas primitivas aflora como uma questão frágil, principalmente quando se trata do 
reconhecimento formal de seus territórios históricos, de seus hábitos, línguas e culturas. É esse embate que se pretende evidenciar no presente texto.

\section{A apreensão do território}

No contexto de inserção do homem como ponto chave na relação da construção e modificação do espaço, tem-se a consolidação do conceito de território como "parte" do espaço apropriado em uma manifestação de poder, na qual se projetam interesses políticos etambém culturais, que atuam como fatores limitantes, separando duas ou mais realidades compreendidas como distantes.

Uma primeira expressão territorial faz-se então como um desdobramento das relações humanas quando organizadas em sociedade, na qual suas vinculações com o espaço, o lugar, tornam-se essenciais para a sua reprodução, e o distinguem. A produção de bens, de moradiae de relações de trocas internas e externas configura-se como o início da expressão legítima da territorialidade.

Raffestin (1993) coloca que esta territorialidade se concretiza na perspectiva da troca e do consumo. Deste modo, compreender a territorialidade somente como um laço com o espaço seria reviver um determinismo sem interesse. Ao contrário, coloca-se sempre como uma relação, mesmo que diferenciada por outros aspectos.

Sack (1986) acrescenta que a territorialidade se apresenta como parte intrínseca do poder e não se basta como meio de criação e manutenção da ordem, mas amplia-se como uminstrumento a criar e manter grande parte do contexto geográfico através do qual nós experimentamos o mundo e conferimos a ele significado.

Ainda acerca da temática, Andrade (1995) afirma que:

A formação de um território dá às pessoas que nele habitam a consciênciade sua participação, provocando o sentido da territorialidade que, de forma subjetiva, cria uma consciência de confraternização entre elas. (Andrade, 1995, p.20).

Neste sentido, a ocupação presencial e a utilização do espaço como fonte dereprodução da vida acarretam a necessidade da afirmação de um território formal, cujoslimites podem ser expressos fisicamente ou cujos limites são intrínsecos a expressões religiosas, mitológicas ou esotéricas. A expressão sócio-cultural de um povo se faz predominantemente através do espaço, como coloca Ratzel (1914):

É fácil convencer-se de que do mesmo modo como não se pode considerarmesmo o Estado mais simples sem o seu território, assim também a sociedade mais simples só pode ser concebida junto com o território que lhe pertence. (Ratzel,1914, p. 73). 
Nesta perspectiva, um conflito claro se forma ao se tratar dos territórios concebidossob a ótica política mundial atual, organizados em estados2, e os territórios indígenas.

Essa realidade é descrita por Diegues (1998) e Haesbaert (2006), quando afirmam que muitos dos povos que ainda não foram atingidos pelo avanço capitalista (como vários povosindígenas) se organizam de modo diferente das sociedades industriais e, portanto, não foramtotalmente incorporadas à lógica do lucro e do mercado, organizando parcela considerável desua produção em torno da auto-subsistência. A relação desses povos com a natureza é muitasvezes simbiótica, e a utilização dos recursos naturais que os cercam só pode ser entendida dentro de uma lógica mais ampla de reprodução social e cultural, distinta da existente na sociedade de reprodução ampliada do capital.

Oliveira (1998) acrescenta especificamente que

diferentemente de Estados-Nação, cujos limites são rigidamente fixados,pois permitem distinguir a aplicação da lei do exercício da guerra, os povos indígenas possuem fronteiras bem mais fluídas, que oscilam regularmente em função de variações demográficas, expedições guerreiras ou movimentos migratórios de vários tipos. Para elas a demanda sobre a terra não é fixada a priori na constituição da própria unidade política, mas pode sofrer mudanças em decorrência da convergência circunstancial e da capacidade de mantê-la face à pressão de outras sociedades vizinhas, também portadoras de características análogas (Oliveira, 1998, p. 292).

Sob esta ótica, as divisões e delimitações de propriedades da terra tão comuns à sociedade capitalista podem soar estranhas às sociedades autóctones. A situação se se complexifica quando o Estado se propõe a mediar estas delimitações, agindo através do exercício de leis que muitas vezes ferem, mesmo que involuntariamente, os preceitos da cultura atingida.

\section{As Contradições Inerentes ao Uso do Poder}

Lidar com diferentes expressões culturais no espaço de modo pacífico sempre foi um desafio à soberania expressa pelo Estado ao longo do tempo. Definir, por exemplo, umareserva indígena no Brasil, é tarefa de extrema complexidade, uma vez que os territórios indígenas estipulados pelo Estado Nacional Brasileiro, estabelecidos no capítulo VIII Art.231, da Constituição de 1988, devem conceder "aos índios sua organização social, costumes,línguas, crenças e tradições e os direitos originários sobre as terras que tradicionalmenteocupam(...)". Especificamente, trata o conceito de terras tradicionalmente ocupadas: “(...) aspor eles habitadas em caráter permanente, as utilizadas para suas atividades produtivas, asimprescindíveis à preservação dos recursos ambientais necessários a seu bem-estar e asnecessárias a sua reprodução física e cultural, segundo seus usos, costumes e tradições".

Desse modo, a concepção do território indígena estaria fortemente atrelada a suaidentidade étnica, que se liga a uma identidade social do grupo, e sua existência depende da Cadernos do Leste 
permanência do grupo. Em contrapartida, de acordo com De Paula (2005), essa continuidade enquanto grupo étnico diferenciado, em termos indigenistas brasileiros, apenas sobreviverá em espaços onde suas manifestações tradicionais, suas identidades, possam ter continuidade, seja na sua manutenção ou na sua atualização perante os novos elementos advindos docontato destes grupos sociais com os segmentos da sociedade nacional em seus contextos geográficos.

Haesbaert (2006) coloca que “(...) assim como a identidade individual, a identidade social é também uma identidade carregada, ao mesmo tempo de subjetividade e deobjetividade (...), que irá aparecer quando no debate da identidade territorial de forma muito nítida, pois por mais que se reconstrua simbolicamente um espaço, sua dimensão mais concreta constitui, de alguma forma, um componente estruturador da identidade" (p. 174).

Desse modo, é possível inferir que a desterritorialização de determinado grupo pode trazer sérios riscos à manutenção de sua cultura, mesmo que seja relocado em outro lugar, o que de maneira alguma implica sua efetiva reterritorialização.

De fato, algumas sociedades tradicionais, como a indígena, possuem grande dependência das condições físicas de seu entorno, além de fazerem uso de referentes espaciais da natureza na construção de suas identidades. (Haesbaert, 2006)

Contudo, não nos cabe aqui fantasiar uma realidade que inicialmente pode soar agradável aos ouvidos de quem a recebe. Certamente que várias sociedades indígenas não estão totalmente inclusas na voraz lógica de reprodução do capital, uma vez que suas relações de poder e produção remetem a uma tradição tribal, mas afastá-la totalmente da lógica desse sistema não se configura como algo sensato, já que podemos pensar que as próprias áreas nas quais os índios estão "habilitados" a viver são definidas pelo capital. A delimitação de reservas indígenas e de áreas ou parques de preservação cultural perpassam inicialmente pela "aceitação" por parte do sistema, e de uma análise de potencial produtivo das áreas referidas, além da existência de cláusulas e acordos que possam moldar tal processo. É nesse contexto que se inserem os índios Tuxá, originais da região do atual município baiano de Rodelas.

O CASO TUXÁ

Identificando-se como "tribo Tuxá, nação Proká, caboclos arco e flecha e maracá", os atuais Tuxá parecem constituir uma das últimas das diversas etnias reunidas a partir do século XVII nas várias missões que se estabeleceram ao longo do curso do Baixo-médio São Francisco. (Funai, 2007)

O povo Tuxá tem uma história marcada pela intensa relação com o rio São Francisco,e sofre, portanto, os efeitos das diversas mudanças que ocorreram ao longo das últimas décadas nesse curso fluvial. Segundo o Cacique Sandro Tuxá, em depoimento obtido em janeiro de 2007, seu povo foi um dos primeiros a serem reconhecidos na Bahia. Parte da história dessa tribo 
remonta a 1640, quando o índio Francisco Rodelas recebeu a patente de capitão dos índios da Coroa portuguesa e ajudou a combater os holandeses que haviam invadido o Brasil. O território da tribo contava com aproximadamente 36 ilhas no rio São Francisco, doadas pela própria Coroa Portuguesa naquela época.

Essa proximidade com o rio São Francisco permitiu o surgimento de inúmeras lendas e rituais relacionados a ele. Toda a dinâmica desse povo estava relacionada ao território em que viviam. A alimentação da tribo, por exemplo, provinha da caça praticada naquela região, da pesca realizada nos rios e da agricultura desenvolvida em algumas ilhas.

A relação dos índios Tuxá com seu território sofreu grande mudança em 1987, quando foram devido à construção da barragem de Itaparica. Todo o seu território foi inundado e a tribo acabou sendo assentada em três cidades distintas, mediante o pagamento de indenização e de uma pensão mensal. Cerca de 89 famílias ficaram em Rodelas (BA), 90 foram reassentadas em Ibotirama (BA) e 9 em Irajá (PE). Perry Scott (2006) relata o processo e o impacto da instalação da represa, e seus desdobramentos:

O projeto de construção da barragem Luiz Gonzaga e o reservatório doLago de Itaparica são muito antigos, e a sua concretização data das décadas, aparentemente remotas, dos anos 1970 e 1980, ou seja, é um processo de cerca de quatro décadas de ação e que tem resultado em uma transformação brutal do cenário cotidiano de uma população numerosa. Para além das 40 mil pessoas diretamente atingidas, que vivem ou viviam diretamente do trabalho na terra, houve um número semelhante de habitantes urbanos diretamente atingidos, que dependem da interação com esses moradores rurais como parte do seu meio de vida. (Scott, 2006, p. 75)

Esse deslocamento das famílias indígenas proporcionou, além da segregação docontingente tribal, uma nova espacialização dos costumes e da cultura dessa tribo, que tendem a ser transformados, influenciados pelas características do novo território ao qual foram submetidos. Segundo Côrtes at al. (2007),

Os Tuxá argumentam que não foram preparados para perder suas terras.A promessa que tiveram era de que iriam ter uma terra melhor. Os funcionários da CHESF até diziam que 'as fruteiras só seriam transportadas das terras da ilha para outro lugar'. Diante disto, muitas vezes, entre eles ouvimos a expressão: 'Nós fomos muito iludidos. Muito mesmo!'. (Côrtes at al., 2007:.2)

O depoimento do cacique Sandro ajuda a esclarecer algumas das consequênciasdiretas desse impacto. Segundo ele,

Primeiro que houve um impacto muito grande na vida primeiramente dosvelhos, por quê? Porque todo mundo era acostumado a pegar os barcos e remar quase uma hora pra ir pra ilha e voltar. Todo mundo acostumado a caçar, pescar, caçar camaleão, capivara, e a mudança foi tão brusca que aqui na aldeia a mortalidade dos velhos foi muito, foi altíssima, que quando eles chegaram aqui não tinha o que fazer não tinha ocupação, eles desciam pra cá e iam pra beira do rio olhar onde ficavam as casas, olhar o pé de árvore, e pra completar a CHESF tãoerrônea deixou as árvores no rio né, tudo de pé, então cada um sabia onde tava a sua casa. (Cacique Sandro Rodelas, depoimento de janeiro de 2007)

Cadernos do Leste 
Consta que em 1994 foi assinado um convênio entre a FUNAI, a CHESF e ascomunidades Tuxá de Rodelas e Ibotirama, com o objetivo de viabilizar sua reestruturaçãoeconômica, através do redimensionamento de um projeto de agricultura irrigada de modo que, segundo Deus (2003), fossem implementadas melhores condições para que o reassentamento da tribo pudesse se realizar de maneira mais digna, de modo a assegurar sua sobrevivência.

Mas essa "sobrevivência" implicou claramente na descaracterização da tradição Tuxá.O texto produzido pela Fundação Nacional do Índio, disponível no site do Ministério da Justiça (http://www.mj.gov.br), aponta estas mudanças:

\begin{abstract}
Tradicionalmente pescadores e agricultores, os Tuxá dedicam-seatualmente quase que de forma exclusiva a agricultura comercial, com base na produção de cebola, cultivo que nos últimos dez anos tem substituído rapidamente os cultivos de subsistência, reduzindo estes a espaços cada vez mais limitados. Utilizam sistema de irrigação, inicialmente apoiado no emprego de energia humana, e presentemente em eletrobombas que atingem toda a superfície cultivadada Ilha da Viúva. A introdução deste sistema de irrigação e as facilidades de acesso à moeda, graças ao comércio da cebola - efetuado no entreposto da cidade de Belém do São Francisco -, provocaram grandes transformações no modo de vida dos Tuxá, incluindo o abandono de atividades tradicionais como o artesanato, e uma crescente dependência de produtos industrializados, que abrangem hoje geladeiras, televisores, etc.
\end{abstract}

E mais:
"Os índios enfrentam, contudo o problema da extrema exiguidade do seuespaço agrícola, que os tem levado a procurar fora, alternativas de ocupação da mão-de-obra excedente, através do trabalho assalariado."(Funai, 2007)

A assinatura desse convênio, portanto, não representou, ao menos para a populaçãoindígena, a manutenção de suas tarefas originais, uma vez que, como já referido, elas se apresentam intensamente relacionadas às características territoriais do local onde esse povo se instala e se reproduz física e culturalmente, mediante suas crenças e tradições.

Deste modo, cabe aqui dizer a respeito da relação que se pode estabelecer entre oterritório antigo e o novo, e os conceitos de fronteira e de limite, enfocados por Hissa (2002), respectivamente, como: um ambiente de mobilidade e de transição; e, uma divisão que se estabelece na tentativa de separar dois mundos distintos que não podem permanecer unidos, ou ainda, um obstáculo à liberdade.

Obviamente que, mesmo em 1640, na época da doação das ilhas aos Tuxá por parte daCoroa Lusitana, não podemos falar de uma liberdade irrestrita à população indígena, tendo em vista a já estabelecida relação de poder. Contudo, é possível imaginar nessa época, como algo intrínseco a um povo indígena, a variabilidade do contorno de "seu" território, configurando-se assim como uma fronteira, tendo susceptibilidade à expansão. Ao analisarmos em uma perspectiva contemporânea, especialmente após a construção da barragem de Itaparica, pode-se perceber que esse contorno do território, antes tido como fronteira, devido à sua mobilidade, Cadernos do Leste 
agora tende a se transformar em limite, voltado para dentro de si mesmo, numa tentativa de se separar essa sociedade indígena da sociedade industrial, ou seja, atuando como fator limitador da liberdade.

No entanto, é factível que essa separação fica apenas na teoria. Dados dos censos de1991 e 2000 demonstram que o contato direto, mesmo que gradativo, com os não índios sãocapazes de alterar o modo de vida dessa população. Além disso, através do índice de vulnerabilidade social familiar (IVSF), proposto por Garcia \& Matos (2007), cuja unidade básica é a família, foi possível perceber o grau de inserção dos indígenas na sociedade local.

O IVSF possibilita análises mais específicas da vulnerabilidade social, tais comoestimativas de diferenciais intra-municipais (área de ponderação e rural/urbano), por raça/cor, atividade e ocupação, levando em consideração as informações sobre o grau de inserção educacional, o grau de inserção econômica local e o grau de inserção habitacional (GARCIA \& MATOS, 2007). O grau de vulnerabilidade é medido de 0 a 1. Quanto mais próximo o índice de 1, maior a vulnerabilidade da população analisada, sendo a recíproca verdadeira.

A primeira tabela (tabela 1), relacionada ao índice de vulnerabilidade de homens emulheres por raça ou cor demonstra que, comparativamente, o grau de vulnerabilidade entre homens de raça/cor diferentes é muito próximo e baixo, menos vulneráveis que as mulheres. Demonstra também que as populações feminina e masculina indígenas apresentaram-se pouco vulneráveis, menos até que a população parda, que corresponde a boa parte da população do município, ao contrário do que geralmente se espera.

Tabela1.Rodelas:2000.Índicedevulnerabilidadedehomensemulheresporraçaoucor.

\begin{tabular}{l|rrr}
\hline Sexo & \multicolumn{1}{c}{ Masculino } & \multicolumn{1}{c}{ FrupoTotal } \\
\hline Corouraça & Indivíduosíndicedevulnerabilidadelndivíduosíndicedevulnerabilidadelndivíduosíndicedevulnerabilidade \\
\hline $\begin{array}{l}\text { BrancaPr } \\
\text { etaParda } \\
\text { Indígenal } \\
\text { gnorado }\end{array}$ & $13270,2512660,2425930,242580,272400,344970,3112050,3513060,3525110,353140,293390,3465$ \\
$30,32--50,0550,05$ \\
\end{tabular}

Fonte:CensolBGE,2000.

A segunda tabela (tabela 2), relacionada ao índice de vulnerabilidade segundo a situação dos domićlios por raça ou cor, mostra um dado interessante: enquanto no meio urbano as condições da população indígena no meio urbano se encontram semelhantes as dos não índios (superando, inclusive, as populações declaradas pretas ou pardas), a população indígena situada na área rural apresenta um índice de vulnerabilidade bastante elevado, de 0,79. Isto demonstra que aqueles indígenas que preferiram o campo a cidade (lembrando que o setor especial de aldeia encontra-se na área urbana), encontram-se em situação que merece atenção do governo local. 
Tabela2.Rodelas:2000.Índicedevulnerabilidadesegundoasituaçãodosdomicíliosporraçaoucor.

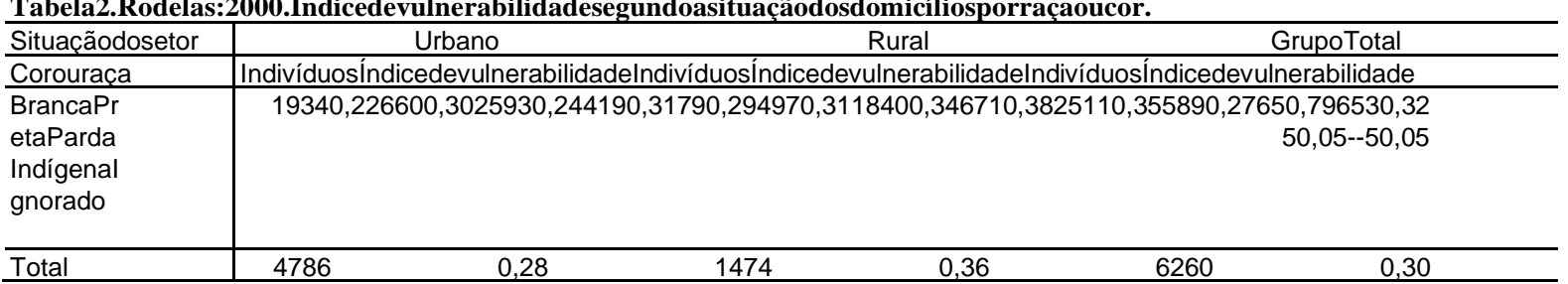

Fonte:CensolBGE,2000.

A terceira tabela (tabela 3), que diz respeito ao índice de vulnerabilidade segundo o tipo de setor por raça ou cor, demonstra que tanto a população indígena que mora no setor especial de aldeia indígena quanto a que mora nos setores comuns ou não especiais apresentam o mesmo grau de vulnerabilidade, ou seja, para o indígena de Rodelas, o fato de morar na aldeia ou não pouco representa para o grau de inserção na sociedade. As populações declaradas brancas, pretas ou pardas moradoras do setor especial de aldeia indígena, por outro lado, apresentaram-se bem menos vulneráveis que as moradoras dos setores comuns ou não especiais. Esse dado evidencia algo curioso: as populações não indígenas estão menos vulneráveis que a população indígena dentro de sua própria aldeia.

\begin{tabular}{|c|c|c|c|}
\hline Tipodesetor & Setorcomumounãoespecial & Setorespecialdealdeiaindígena & GrupoTotal \\
\hline Corouraca & \multicolumn{3}{|c|}{ IndivíduosíndicedevulnerabilidadeIndivíduosíndicedevulnerabilidadelndivíduosíndicedevulnerabilidade } \\
\hline $\begin{array}{l}\text { BrancaPr } \\
\text { etaParda } \\
\text { Indígenal } \\
\text { gnorado }\end{array}$ & \multicolumn{3}{|c|}{$\begin{array}{r}25610,25330,0825930,244840,31140,164970,3124940,35170,1525110,352650,323880,326530,325 \\
0,05--50,05\end{array}$} \\
\hline Total & 5808 & 0,29 & 6260 \\
\hline
\end{tabular}

Fonte:CensolBGE,2000.

No tocante a tradição indígena Tuxá, no que diz respeito à agricultura de subsistência, apenas $8,6 \%$ dos declarados índios trabalharam a lavoura. Este número é curioso e, apesar da taxa ser superior à média municipal (4,8\%), demonstra que existe um grande percentual de índios ociosos ou inseridos em outras atividades (tabela 4).

Tabela4.Rodelas:1991.Populaçãoquenasemanatrabalhouemcultivoetc.Paraalimentaçãodepessoasresidentesnodomicílio em1991.

\begin{tabular}{l|cccc}
\hline Trabalhou & Indígenas & \%Residente & Nãolndígenas & \%Residente \\
\hline Sim & 39 & 3,56 & 103 & 4,30 \\
Não & 1058 & 96,44 & 2298 & 95,70 \\
\hline Total & 1097 & 100 & 2401 & 100 \\
\hline Fonte:CensolBGE,1991. & & &
\end{tabular}

Ao se tratar de aspectos religiosos, todos os declarados índios se disseram cristãos, sendo que 89,3\% declaram-se adeptos ao catolicismo apostólico romano (tabela 5). Essa inserção na lógica religiosa ocidental indica tanto uma tendência ao abandono gradativo das práticas religiosas tradicionais quanto uma clara aproximação aos preceitos ocidentais. 
Tabela 5. Rodelas: 1991.Religiãoda populacão em1991.

\begin{tabular}{l|cccc}
\hline TipodeReligião & Indígenas & \%Residente & Nãolndígenas & \%Redisente \\
\hline Semreligião & & $91,382734,8758389,28490487,46578,734137,3700,0000,00$ & \\
CatólicaApostólicaRomanaE & 4 & 0,61 & 17 & 0,30 \\
vangélicos & & & & \\
$\begin{array}{l}\text { Espírita,Kardecista } \\
\text { Semdeclaração }\end{array}$ & & & & \\
\hline TotaldoGrupo & 653 & 100 & 100 \\
\hline
\end{tabular}

Fonte:CensolBGE,1991.

Deus (2003) acrescenta que, apesar de os Tuxá apresentarem, em primeira análise, alternativas modestas de subsistência via agricultura de vazante ou artesanato, por exemplo, também demonstram ter controle sobre seu espaço territorial, participando inclusive do contexto político local e dominando um processo produtivo capaz de lhes garantir a sua reprodução física e sociocultural.

Essa simples análise acerca das informações provenientes dos censos é capaz de demonstrar o quanto a cultura ocidental está arraigada na sociedade indígena Tuxá, que como foi demonstrado, está tão inserida na lógica da cidade quanto os não-índios, apresentando muitas vezes condições de vida melhor que a deles. De fato, os processos de mundialização, relacionados à assimilação e familiarização com os símbolos da modernidade, são intrínsecos a lógica do índio aldeado, que transitam entre a realidade da aldeia, fragilmente protegida das linhas de atuação desses processos, e na função que a pouco lhes foi ofertada, a de cidadãos mundiais (Garnelo \& Sampaio, 2006).

\section{Reflexões acerca da problemática Tuxá}

Como avaliar impactos socioambientais no campo simbólico quando o pragmatismo e racionalidade das nações consumistas e desenvolvimentistas ignoram, absolutamente, a dimensão espiritual/afetiva dos cálculos, das trocas, das recompensas financeiras. Como quantificar e negociar algo dessa dimensão? Como pagar o apagão da cosmologia indígena? (Marques, 2007, p.12)

Nessa análise, nota-se que a alteração de limites e fronteiras apresenta forte ligação com os processos de modernização (Hissa, 2002), uma vez que esses tendem a moldar novos contextos sociais, políticos e econômicos, que, por sua vez, geram diferentes cenários responsáveis pela variação conceitual dos termos, no tempo e no espaço. Sendo o limite “(...) apenas uma manifestação do controle, do governo, do domínio, da propriedade" (Hissa, 2002:39), pode-se entender a variação de tal termo, assim como da fronteira, como uma mudança de poder que se estabelece, podendo gerar marcas mais profundas ou mais sutis

No tocante ainda ao avanço da modernidade, e da chamada ciência moderna, tem-se, paralelamente, em sentido contrário, o recuo da crença mitológica, que pode ser associada à 
questão indígena estudada, uma vez que aceitações baseadas na crendice tendem a perder espaço para explicações notadamente científicas, assim como a sociedade tribal tende a perder espaço para a sociedade industrial, de reprodução rápida e massiva, restando-lhe o confinamento em áreas ou reservas de preservação, de caráter pontual, as quais são limitadas por latitudes imaginárias ou pelos chamados acidentes geográficos.

Este recuo de crenças pode ser claramente percebido como um desdobramento da desterritorialização e do confinamento aos quais os índios Tuxá foram submetidos, como coloca o cacique Sandro:

Nos temos assim algumas tradições, que a gente fazia oferenda a mãe da água e é interessante, mas quando a gente tem que fazer alguma oferenda, alguma prece, o pessoal sai daqui, pega um barco e vai lá no rio velho, que é no Cristo "Serrote". Então os índios não considera esse rio1 como um rio, como que o rio morreu, como que o rio é vivo um rio que não corre, que não anda. (Cacique Sandro Rodelas, depoimento de janeiro de 2007)

Resta, enfim, mais um problema que pode ser somado à dita crise da modernidade, no âmbito social: como evitar a segregação e ao mesmo tempo preservar a tradição de uma sociedade que se configura de maneira tão distinta aos padrões modernos, superando o problema da territorialidade? Parece-nos muito radical e insensato propor o fim de uma ou outra sociedade para resolver o problema, assim como a ideia de inserção total da sociedade tribal na lógica moderna do capital se configuraria como uma imposição que entraria em choque com os preceitos de democracia e liberdade tão difundidas na sociedade tal qual a concebemos. O enclausuramento em áreas de proteção, por outro lado, significaria tanto um entrave à expansão econômica e demográfica do Estado, quanto uma limitação ao modo de reprodução indigenista que, como já citado, muitas vezes não possui limites transcendentalmente definidos.

Talvez uma integração moderada da sociedade tribal na sociedade industrial, de modo a permitir que os índios tenham uma maior capacidade de divulgar e permear suas tradições e costumes configurese como uma das alternativas para resolver esse impasse, e impedir que, cedo ou tarde, essas tradições sejam totalmente inseridas na lógica do capital e se percam em lembranças remotas, somente guardadas em depoimentos e/ou documentários passados, bem como na memória de algumas poucas pessoas.

O debate, então, permanece.

\section{AGRADECIMENTOS:}

Aos Tuxá de Rodelas, que tão bem nos receberam.

Ao projeto "População e territorialidades chaves na rede de cidades da bacia do São Francisco", coordenado pelo professor Ralfo Matos, que propiciou o contato com a causa Tuxá.

Ao professor Célio Augusto Horta, pelas orientações relevantes e oportunas. 


\section{REFERÊNCIASBIBLIOGRÁFICAS}

ANDRADE, M. C.. A Questão do Território no Brasil. São Paulo: Editora Hucitec. 1995.

BRASIL, Constituição. (1988), Constituição: República Federativa do Brasil. Brasília, Senado Federal, Centro Gráfico.

CÔRTES, C. N.; MOTTAA, E. ; ARAUJO TUXÁ, M. S.. O povo Tuxá e a Barragem de Itaparica: conseqüêcias, lutas, desafios e espaços socioeducativos. In: I Encuentro Latinoamericano Ciencias Sociales y Represas e II Encontro Brasileiro Ciências Sociais e Barragens, 2007, Salvador. I Encuentro Latinoamericano Ciencias Sociales y Represas e II Encontro Brasileiro Ciências Sociais e Barragens. Salvador, 2007.

DEUS, J. A. S.. Territorialidade e cultura dos povos indígenas (Áreas Norte-Amazônica e Juruá Purus). Tese (Doutorado). Universidade Federal do Rio de Jnaneiro, IGEO, 2003.

DE PAULA, S. A. A.. Territorialidade indígena na amazônia brasileira do século xxi: o caso jamamadi. Dissertação de mestrado. Universidade Federal do Paraná. 2005.

DIEGUES, A. C. O Mito Moderno da Natureza Intocada. São Paulo: Editora Hucitec. 1998.

FUNAI. Disponível em <http://www.funai.gov.br/>.Acessado em 28/11/2007 GARNELO, L.; SAMPAIO, S.. Globalização e ambientalismo: etnicidades

polifônicas na Amazônia. História, Ciências, Saúde. Manguinhos, Rio de Janeiro, v. 12, n. 3, p. 755-767, 2006.

GARCIA, R. A.. Apresentador de Trabalho: Modernização e crescimento populacional nos municípios de Minas Gerais: uma aplicação do método Grade of membership. Sessão temática 9: Mirgaçòes e crescimento populacional. IX Seminário sobre a Econômia Mineira. 2000.

GARCIA, R. A.; MATOS, R.. A distribuição espacial da vulnerabilidade social das famílias brasileiras. Trabalho apresentado no Seminário População, Pobreza e Desigualdade. 2007. Belo Horizonte.

HAESBAERT, R.. O mito da desterritorialização: do fim dos territórios à multiterritorialidade. Rio de Janeiro: Bertrand do Brasil, 400p. $2^{\text {a }}$ Ed. 2006.

HISSA, C. E. V.. A mobilidade das fronteiras : inserções da geografia na crise da modernidade. Belo Horizonte: UFMG, 2002. 316 p (Humanitas;)

JUSTIÇA, Ministério da. Disponível em <http://www.mj.gov.br>. Acessado em 26/11/2007

MARQUES, J.. Barragens: Destruição da Cultura Material e Ameaças de Territórios Tradicionais dos Povos Indígenas do São Francisco. In: I Encuentro Latinoamericano Ciencias Sociales y Represas, II Encontro Brasileiro Ciênciais Sociais e Barragens, 2007, Salvador. I Encuentro Latinoamericano Ciencias Sociales y Represas, II Encontro Brasileiro Ciênciais Sociais e Barragens. Salvador : EDUFBA, 2007. v. 1.

Cadernos do Leste 
OLIVEIRA, J. P.. 1998. Instrumentos de bordo: expectativas e possibilidades de trabalho do antropólogo em laudos periciais. In: Indigenismo e Territorialização: Poderes, rotinas e saberes coloniais no Brasil Contemporâneo. Org. OLIVEIRA, João Pacheco. Rio de Janeiro: Contra Capa Livraria Ltda, p. 269-295.

RAFFESTIN, C.. Por uma geografia do poder. São Paulo: Ática. 1993.

SACK, R. D.. Human territoriality: its theory and history. Cambridge: Cambridge University, 1986.

SCOTT, P.. Re-assentamento, Saúde e Insegurança em Itaparica: um modelo de vulnerabilidade em projetos de desenvolvimento. In: Saúde e Sociedade v.15, n.3, p.74-89, set-dez 2006.

SCHNEIDER, S.; PEYRÉ TARTARUGA, I. G.. Território e abordagem territorial: das referências cognitivas aos aportes aplicados à análise dos processos sociais rurais. In. Raízes: Revista de Ciências Sociais. Campina Grande. Vol. 23, no 01 e 02, p. 99 a 117. 2004.

SOUZA JÚNIOR, F. F.; LOPES, B. M.. A importância do direito dos índios para a manutenção da identidade brasileira. Jus Navigandi, Teresina, ano 8, n. 286, 19 abr. 2004. Disponível em: <http://jus2.uol.com.br/doutrina/texto.asp?id=5110>. Acesso em: 30 nov. 2007.

Depoimentos gravados e/ou anotados em janeiro de 2007:

- Cacique Sandro Rodelas 